\title{
MALDI-MS Analysis of Peptides Modified with Photolabile Arylazido Groups
}

\author{
William Low, James Kang, Michael DiGruccio, Dean Kirby, \\ Marilyn Perrin, and Wolfgang H. Fischer \\ The Clayton Foundation Laboratories for Peptide Biology, The Salk Institute, La Jolla, California, USA
}

\begin{abstract}
The ability of MALDI-MS to analyze photolabile arylazido peptide derivatives was investigated. Peptides containing UV-labile p-azidobenzoyl groups were subjected to MALDI-MS analysis in a variety of matrices. As standard MALDI-MS employs a UV laser (337 nm), we investigated conditions that would allow detection of the intact molecule ions for these light-sensitive peptides. When using $\alpha$-cyano-4-hydroxycinnamic acid (ACHC) or 2,5 dihydroxybenzoic acid (DHB) as the matrix, photoinduced degradation products were prevalent. In contrast, when employing the matrix sinapinic acid, the intact molecule ion corresponding with the azido peptide was the predominant signal. The protection of photolabile azido derivatives correlates with the UV absorbance properties of the matrix employed, i.e., sinapinic acid, which exhibits a strong absorbance near $337 \mathrm{~nm}$, most efficiently protects the azido derivative from photodegradation. (J Am Soc Mass Spectrom 2004, 15, 1156-1160) (c) 2004 American Society for Mass Spectrometry
\end{abstract}

$\mathrm{P}$ hotoactivatable reagents are powerful tools in the study of molecular interactions [1,2]. The most commonly used photoactivatable group for protein and peptides is the arylazido group. Arylazido modified peptides can be prepared by reacting an activated p-azidobenzoic acid derivative with amino groups present either at the $\mathrm{N}$-terminus or at lysyl side chains. Activation of these p-azidobenzoyl peptides is achieved by UV-light irradiation resulting in a loss of nitrogen $\left(\mathrm{N}_{2}\right)$ and formation of a reactive nitrene intermediate. The reactive species can then form a covalent bond with a nearby protein chain. The reaction is likely to take place in the vicinity of the activated species. The covalent crosslink can thus lead to the identification of a binding site, e.g., of a ligand and a receptor or a substrate and an enzyme.

A convenient way of preparing azidobenzoyl peptides involves reacting the peptide with an activated azidobenzoic acid derivative, such as the hydroxysuccinimidyl ester. These reagents react with the primary amino groups in the peptide, the N-terminal amino group or the $\varepsilon$-amino group in lysyl residues. In cases where several amino groups are present, one or more of these reactive groups can become modified. It is important to determine which amino group carries the modification to reproducibly generate the one that exhibits the highest affinity for its receptor or other binding partner. The full characterization of photolabile compo-

Published online June 19, 2004

Address reprint requests to Dr. W. Fischer, The Clayton Foundation Laboratories for Peptide Biology, The Salk Institute, 10010 N. Torrey Pines Road, La Jolla, CA 92037, USA. E-mail: Fischer@salk.edu nents represents a challenge as many analytical procedures involve the use of UV light, e.g., UV detection during HPLC purification and UV laser irradiation during MALDI-MS analysis. We have therefore investigated conditions for MALDI-MS analysis that would allow the detection of intact photoactivatable peptides.

The corticotropin releasing factor (CRF) family of neuropeptides is involved in essential responses to stress [3]. Centrally, these peptides activate the pituitary adrenal axis. Peripheral effects include an influence on blood pressure as well as immune and inflammatory responses [4]. To date four members of the CRF peptide family have been characterized in mammals [5]. The receptors for the CRF peptides belong to the G-protein coupled seven transmembrane receptor family. Two subtypes of CRF receptors have been characterized that exhibit differential affinity for the ligands [6, 7]. We have recently identified the first extracellular domain of the CRF type I receptor as playing a major role in agonist and antagonist binding $[8,9]$. In particular the synthetic peptide antagonist Astressin binds the first extracellular portion with high affinity. The present study resulted from our interest in generating an Astressin analog that could be used to photolabel the binding region of the first extracellular domain of the type I CRF receptor.

\section{Experimental}

Azidobenzoylation of Astressin

DTyr12-astressin $(0.07 \mathrm{mg})$ was reacted with N-hydroxysulfosuccinimidyl-4-azidobenzoate $(1.8 \mathrm{mg}$, Pierce 
Chemical Company, Rockford, Illinois) in $20 \mathrm{mM}$ sodium phosphate buffer $(\mathrm{pH} \mathrm{7)}$ for $70 \mathrm{~min}$ at RT. The reaction mixture was separated by reversed-phase HPLC. The mobile phase consisted of $0.05 \%$ trifluoroacetic acid in water (A buffer) or in $90 \%$ acetonitrile/ water (B buffer). A narrow bore C-18 column from Vydac (Hesperia, CA) was employed (particle size 5 $\mu \mathrm{m}$, column dimensions: $2.1 \times 150 \mathrm{~mm}$ ). UV absorbance was monitored at $210 \mathrm{~nm}$. The three major components were collected and further analyzed. All manipulations were carried out in a darkened room and samples were kept in tubes wrapped in aluminum foil.

\section{V8 Peptidase Digest of Modified Peptides}

The modified peptides collected after HPLC separation (amount estimated at 10-20 $\mu \mathrm{g}$ each) were lyophilized and digested with $1 \mu \mathrm{g}$ V8 protease (Roche Biochemicals, IN) in $50 \mu \mathrm{l}$ ammonium bicarbonate buffer (50 $\mathrm{mM}, \mathrm{pH}$ 8.3). The digests were resolved by reversed phase HPLC. The fractions were analyzed by MALDI-MS to identify the modified proteolytic fragments.

\section{MALDI-MS Analysis}

MALDI-MS spectra were measured on an ABI-Perseptive DE-STR instrument. The instrument employs a nitrogen laser $(337 \mathrm{~nm})$ at a repetition rate of $20 \mathrm{~Hz}$. The spectra were recorded in the delayed extraction mode. The accelerating voltage was $20 \mathrm{kV}$. All spectra were recorded in the positive reflector mode. Laser power was kept to a minimum for all spectra which are sums of 100 laser shots. The reported $\mathrm{m} / \mathrm{z}$ values were rounded to the nearest integer for clarity; all measured masses were within $100 \mathrm{ppm}$ of the calculated values. Matrices (sinapinic acid and $\alpha$-cyano-4-hydroxycinnamic acid) were prepared as saturated solutions in $0.3 \%$ trifluoroactetic acid and 30\% acetonitrile. The matrix 2,5-dihydroxybenzoic acid was prepared at 1 $\mathrm{mg} / \mathrm{ml}$ in the same solvent mixture. All chemicals were obtained from Sigma Chemical Company (St. Louis, MO). Samples ( $1 \mathrm{pmol}$ in $0.5 \mu \mathrm{l}$ ) were mixed with an equal volume of matrix solution on the target and allowed to dry in a darkened room. Throughout the procedure the target was kept away from light sources.

\section{UV Spectra}

UV spectra were recorded at a concentration of $45 \mu \mathrm{M}$ in $0.3 \%$ trifluoroacetic acid and $30 \%$ acetonitrile/water as solvent. This is the same solvent used for MALDI matrices in the analyses described above.

\section{Results and Discussion}

The corticotropin releasing factor antagonist DTyr ${ }^{12}$ astressin [10] was reacted with N-hydroxysulfosuccinimidyl-4-azidobenzoate. The peptide contains one lysine residue and a free N-terminal amino group.
Acylation can thus result in modification of either of the amino groups or of both. Consistent with this fact, three major products were isolated after HPLC separation. Inspection of the sequence revealed that digestion with V8 protease would generate separate fragments containing the N-terminal amino acid and the single lysyl residue. Digestion with V8 protease was carried out in ammonium bicarbonate buffer at $\mathrm{pH} 8.3$ for all three products. An aliquot of the digestion mixture was resolved by reversed phase HPLC. The HPLC fractions as well as the crude digests were subjected to MALDI-MS analysis. Analyses presented here were carried out on the HPLC isolated peptides. For the C-terminal peptide H-Gln-Leu-Ala-Gln-Glu*-Ala-HisLys*-Asn-Arg-Lys(pAzbz)-Leu-Nle-Glu-OH (AzidoCtAst) the modified lysine is represented by Lys(pAzbz); the side chains of Glu* and Lys* are connected by a lactam bridge. The N-terminal peptide pAzbz-TyrHis-Leu-Leu-Arg-Glu-OH (Azido-NtAst) is modified by the p-azidobenzoyl moiety at the N-terminal tyrosine's $\alpha$ amino group, represented by pAzbz-Tyr. Initial analysis of the C-terminal peptide were carried out employing $\alpha$-cyano-4-hydroxycinnamic acid (ACHC) as the matrix. This matrix is commonly used when analyzing peptides with molecular weights $<5000$ Da. The modified peptides exhibited a strong signal 26 mass units lower than that expected for the benzoylazido peptides (Figure 1a). Additional weak signals were observed that were 10 and 43 mass units lower than expected for the $[\mathrm{M}+\mathrm{H}]^{+}$of the modified peptide. No significant signal was observed at $\mathrm{m} / \mathrm{z}=$ 1805, the expected mass for the intact Azido-CtAst ([M $\left.+\mathrm{H}]_{\text {mono }}^{+}=1804.96 \mathrm{Da}\right)$. The major signal at $\mathrm{m} / \mathrm{z}=$ 1779 is consistent with a loss of nitrogen $\left(\mathrm{N}_{2}\right)$ and addition of 2 hydrogen atoms $(\mathrm{H})$ to the nitrene which could have occurred during storage or purification of the peptide or during analysis in the mass spectrometer. To investigate these possibilities, the modified peptides were analyzed in different matrices by MALDI-MS and, to utilize an ionization procedure which does not involve UV-irradiation, by ESI ion trap MS.

Figure $1 \mathrm{~b}$ shows the MALDI-MS spectrum obtained for Azido-CtAst using 2,5 dihydroxybenzoic acid (DHB) as the matrix. The predominant species is again observed at $m / z=1779$ with a minor signal present at $m / z=1795$ while no sigificant signal could be observed for the intact arylazido peptide (calculated $[\mathrm{M}+\mathrm{H}]^{+}=$ 1805).

When using sinapinic acid as the matrix, the signal corresponding to the intact photolabile peptide at $\mathrm{m} / \mathrm{z}=$ 1805 becomes the predominant signal (Figure 1c). In addition, a strong signal at $m / z=1779$ and a very weak signal at $m / z=1762$ were observed. To determine if any of the photodegradation had taken place outside the mass spectrometer, the analysis was also performed by electrospray ionization on an ion trap instrument. The predominant signal corresponded with the intact arylazido peptide and none of the degradation products were observed (data not shown). This indicates that the 

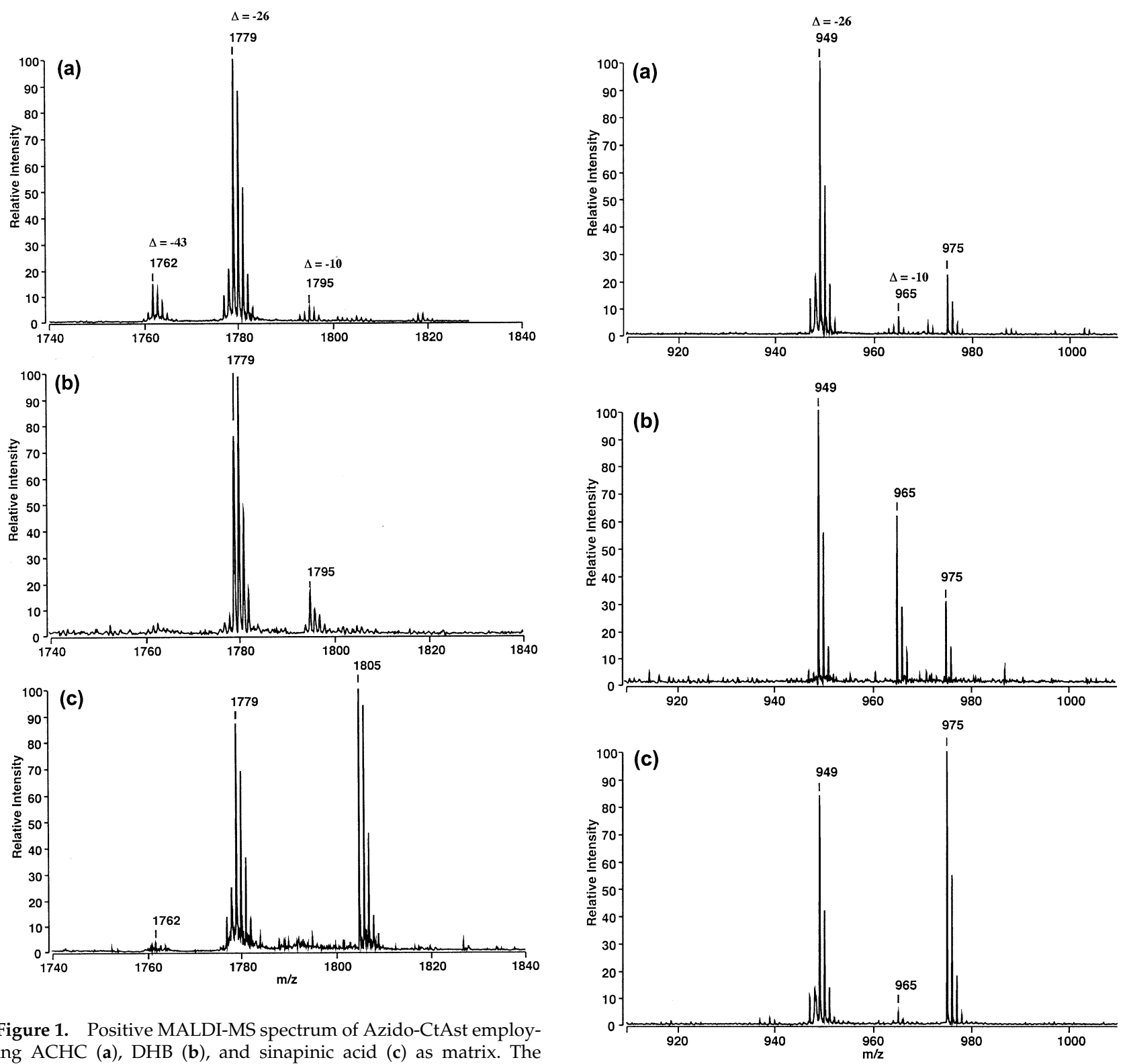

Figure 1. Positive MALDI-MS spectrum of Azido-CtAst employing $\mathrm{ACHC}(\mathbf{a}), \operatorname{DHB}(\mathbf{b})$, and sinapinic acid (c) as matrix. The signal for intact Azido-CtAst at $\mathrm{m} / \mathrm{z}=1805$ (calculated [M + $\mathrm{H}^{+}{ }_{\text {mono }}=1804.96 \mathrm{Da}$ ) is only detectable when using sinapinic acid as the matrix. Degradation products are observed at $\mathrm{m} / \mathrm{z}=$ 1795,1779 , and 1762 .

photodegradation products were formed in the MALDI mass spectrometer.

The N-terminal modified peptide (Azido-NtAst) was analyzed employing the same matrices with similar results (Figure 2). For this peptide, the mass of the intact azidobenzoyl peptide was observed at $\mathrm{m} / \mathrm{z} 975$ (calculated $\left.[\mathrm{M}+\mathrm{H}]^{+}=975.48\right)$ in all three matrices. The signal was the predominant one when using sinapinic acid (Figure 2c) while in both ACHC and DHB, the signal at $m / z=949$ was the strongest. An additional signal of varying intensity was observed at $m / z=965$.

The spectra presented here were obtained employing the minimum laser power for a signal-to-noise ratio of at least 50:1. It was found that increasing laser power

Figure 2. Positive MALDI-MS spectrum of Azido-NtAst employing $\mathrm{ACHC}(\mathbf{a}), \mathrm{DHB}(\mathbf{b})$, and sinapinic acid (c) as matrix. The signal for intact Azido-CtAst at $\mathrm{m} / \mathrm{z}=975$ (calculated $[\mathrm{M}+$ $\left.\mathrm{H}^{+}{ }_{\text {mono }}=975.48 \mathrm{Da}\right)$ is the predominant species when using sinapinic acid as the matrix. Degradation products are observed at $m / z=965$ and 949 .

beyond this threshold lead to an increase in signal intensity for the photodegradation products (data not shown). The amount of sample loaded onto the target did not have a major influence on the ratio between the signals for intact and degradated pepides unless the quantity became marginal and required an increase in laser power to become detectable.

The mass differences between the expected $[\mathrm{M}+$ $\mathrm{H}]^{+}$of the arylazido peptides and their degradation products are indicated in Figures 1a and 2a. The photodegradation products are observed as signals at $[\mathrm{M}+$ $\mathrm{H}-10]^{+},[\mathrm{M}+\mathrm{H}-26]^{+}$and $[\mathrm{M}+\mathrm{H}-43]^{+}$, 


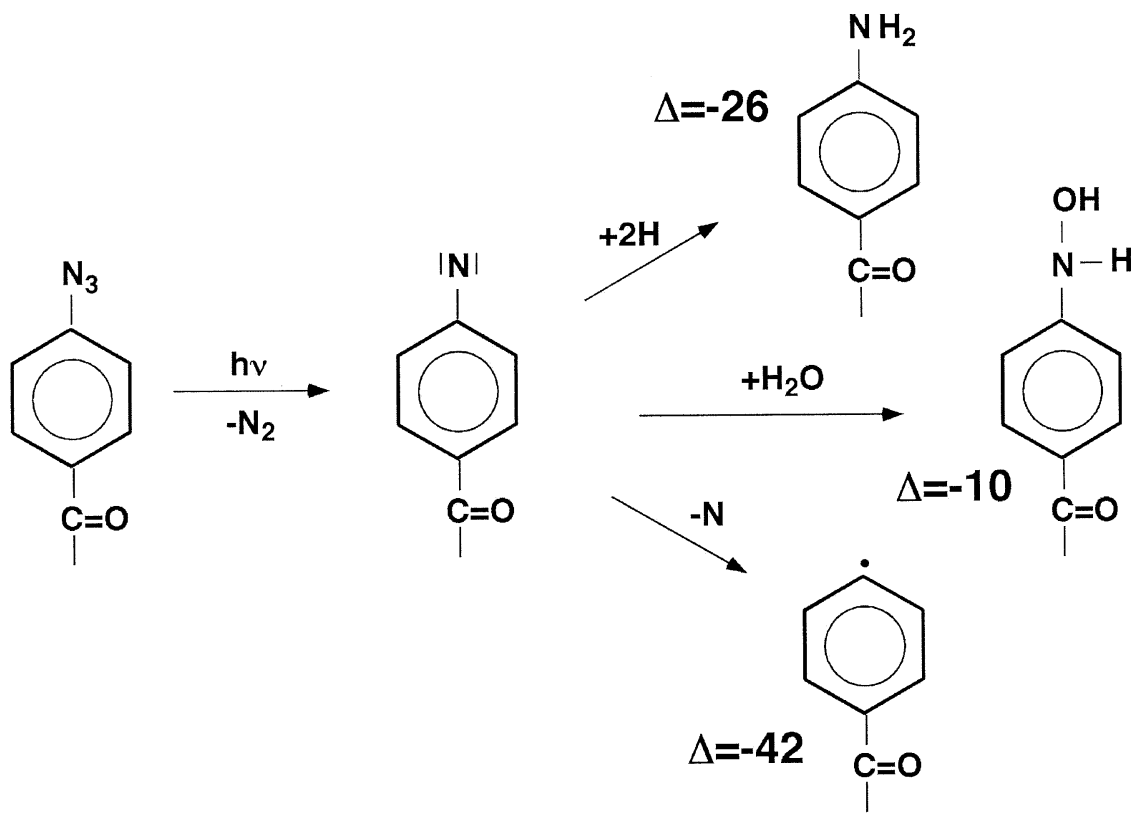

Scheme 1. Photodegradation products of the benzoylazido group. The mass differences to the starting material and possible end products are shown.

respectively. The chemistry of azido compounds and that of their photoactivation has been studied extensively [1,2]. The first step of the activation involves elimination of $\mathrm{N}_{2}$ and formation of the reactive nitrene. The nitrene then reacts by insertion into $\mathrm{C}-\mathrm{H}$ or $\mathrm{C}-\mathrm{C}$ bonds. Alternatively, other reactive intermediates such as the seven-membered heterocyclic tropolone can form and in turn react with functional groups in neighboring proteins. The MALDI-MS analysis of ATP azido derivatives has been described by Chen et al. [11]. These authors recorded MALDI spectra in the negative mode and detected mainly $[\mathrm{M}-\mathrm{H}-26]^{-}$and $[\mathrm{M}-\mathrm{H}-12]^{-}$ species. The $[\mathrm{M}-\mathrm{H}-26]^{-}$is proposed to arise from elimination of $\mathrm{N}_{2}$ and addition of $2 \mathrm{H}$ whereas the [M $\mathrm{H}-12]^{-}$is likely to result from $\mathrm{N}_{2}$ elimination and addition of oxygen. The species at $[\mathrm{M}-\mathrm{H}-10]^{-}$, which is not observed in the analysis of azido-ATP is proposed to be the result of $\mathrm{N}_{2}$ elimination and addition of $\mathrm{H}_{2} \mathrm{O}$. Based on the study by Chen et al. [11] and our observations, we propose the following interpretation of the masses observed for the photodegradation products (Scheme 1). The $[\mathrm{M}+\mathrm{H}-10]^{+}$species results from elimination of $\mathrm{N}_{2}$ and addition of $\mathrm{H}_{2} \mathrm{O}$, possibly leading to the formation of a hydroxylamine. The species at $[\mathrm{M}+\mathrm{H}-26]^{+}$is most likeley the result of $\mathrm{N}_{2}$ elimination and addition of 2 hydrogen atoms which could lead to the formation of an amine. Loss of the azido group $\left(\mathrm{N}_{3}\right)$ should lead to a species at $[\mathrm{M}+\mathrm{H}-$ $42]^{+}$, whereas we observe a signal at $\Delta=-43$. We interpret this as a non-protonated species, thus [M $42]^{+}$corresponds with the positively charged molecule ion that has lost the $\mathrm{N}_{3}^{-}$anion.

To investigate the differences in the matrices ability to protect photolabile peptides from degradation by laser illumination, we recorded UV spectra of the matrices employed (Figure 3). Of the the three matrices, sinapinic acid exhibits the highest absorbance near the wavelength of the laser employed $(337 \mathrm{~nm})$. The absorbance of both ACHC and DHB is approximately 3-fold lower in this wavelength region. The matrices employed for this study are chemically similar compounds, i.e., they are aromatic carboxylic acids. All three carry hydroxyl functions on the aromatic ring and two (ACHC and sinapinic acid) are cinnamic acid derivatives. While it cannot be excluded that differences in their gas phase chemistry play a role in their reactivity towards azido modified peptides, we propose that their light absorbance characteristics are a predominant factor. Thus, the ability of sinapinic acid to absorb the excitation laser's light is likely to lead to a protection of the analyte from photodegradation.

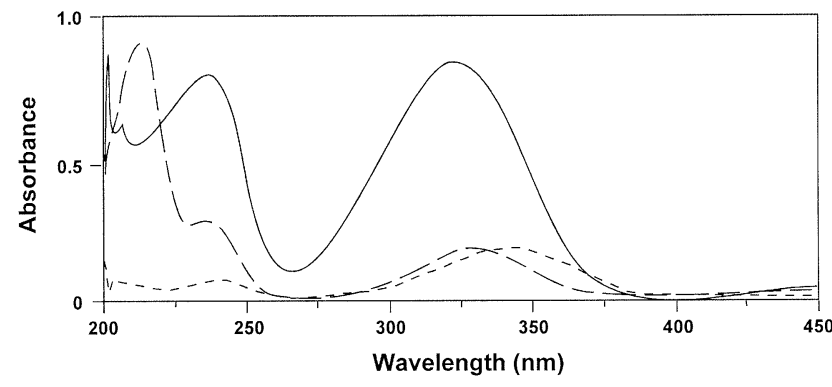

Figure 3. UV spectra of sinapinic acid (solid line), ACHC (short dashed line), and DHB (long dashed line). The matrices were dissolved at a concentration of $45 \mu \mathrm{M}$ in $0.3 \%$ trifluoroacetic acid, $30 \%$ acetonitrile/water. 


\section{Conclusions}

The results presented here show that azidobenzoyl peptides undergo photoactivation during MALDI-MS analysis to a different extent depending the matrix employed. Analysis by MALDI-MS resulted in the formation of mainly two reaction products during laser irradiation, the $[\mathrm{M}+\mathrm{H}-26]^{+}$and $[\mathrm{M}+\mathrm{H}-10]^{+}$ species, when ACHC or DHB are used as a matrix. When sinapinic acid is employed, the authentic azido peptide $[\mathrm{M}+\mathrm{H}]^{+}$becomes the predominant signal. The reaction products are proposed to result from loss of $\mathrm{N}_{2}$ and the addition of $2 \mathrm{H}$ or $\mathrm{H}_{2} \mathrm{O}$, respectively. These differences in signal abundance for the degraded species are likely a consequence of the UV absorbance characteristics of the matrix molecule compared to the analyte. The matrix sinapinic acid appears to protect the analyte from UV irradiation with the highest efficiency.

\section{Acknowledgments}

The authors thank Dr. Jean Rivier and Ron Kaiser for the synthetic peptides used in this study. This work was supported by grants from NIH (DK26741 and HD13527) and NSF (0216654). The Mass Spectrometry Laboratory at the Salk Institute is generously supported by the Vincent J. Coates Foundation.

\section{References}

1. Chowdhry, V.; Westheimer, F. H. Photoaffinity Labeling of Biological Systems. Annu. Rev. Biochem. 1979, 48, 293-325.

2. Hazum, E. Photoaffinity Labeling of Peptide Hormone Receptors. Endocr. Rev. 1983, 4, 352-362.

3. Vale, W.; Spiess, J.; Rivier, C.; Rivier, J. Characterization of a 41 Residue Ovine Hypothalamic Peptide that Stimulates the Secretion of Corticotropin and $\beta$-Endorphin. Science 1981, 213, 1394-1397.
4. Vale, W. W.; Vaughan, J. M.; Perrin, M. H. The CorticotropinReleasing Factor (CRF) Family of Ligands and Their Receptors. Endocrinologist 1996, 7, S3-S9.

5. Lewis, K.; Li, C.; Perrin, M. H.; Blount, A.; Kunitake, K.; Donaldson, C.; Vaughan, J.; Reyes, T. M.; Gulyas, J.; Fischer, W.; Bilezikjian, L.; Rivier, J.; Sawchenko, P. E.; Vale, W. W. Identification of Urocortin III, an Additional Member of the Corticotropin-Releasing Factor (CRF) Family with High Affinity for the CRF2 Receptor. Proc. Natl. Acad. Sci. U.S.A. 2001, 98, $7570-7575$.

6. Chen, R.; Lewis, K. A.; Perrin, M. H.; Vale, W. W. Expression Cloning of a Human Corticotropin Releasing Factor (CRF) Receptor. Proc. Natl. Acad. Sci. U.S.A. 1993, 90, 8967-8971.

7. Perrin, M. H.; Donaldson, C.; Chen, R.; Blount, A.; Berggren, T.; Bilezikjian, L.; Sawchenko, P.; Vale, W. W. Identification of a Second Corticotropin-Releasing Factor Receptor Gene and Characterization of a cDNA Expressed in Heart. Proc. Natl. Acad. Sci. U.S.A. 1995, 92, 2969-2973.

8. Perrin, M. H.; Fischer, W. H.; Kunitake, K. S.; Craig, A. G.; Koerber, S. C.; Cervini, L. A.; Rivier, J. E.; Groppe, J. C.; Greenwald, J.; Nielsen, S. M.; Vale, W. W. Expression, Purification and Characterization of a Soluble Form of the First Extracellular Domain of the Human Type 1 Corticotropin Releasing Factor Receptor. J. Biol. Chem. 2001, 276, 3152831534.

9. Perrin, M.; DiGruccio, M.; Koerber, S.; Rivier, J.; Kunitake, K.; Bain, D.; Fischer, W. H.; Vale, W. A Soluble Form of the First Extracellular Domain of Mouse Type $2 \beta$ Corticotropin Releasing Factor Receptor Reveals Differential Ligand Specificity. J. Biol. Chem. 2003, 278, 15595-15600.

10. Rivier, J. E.; Kirby, D. A.; Lahrichi, S. L.; Corrigan, A.; Vale, W. W.; Rivier, C. L. Constrained Corticotropin Releasing Factor (CRF) Antagonists (Astressin Analogues) with Long Duration of Action in the Rat. J. Med. Chem. 1999, 42, 31753182.

11. Chen, X.; Siems, W. F.; Asbury, G. R.; Yount, R. G. Fingerprint Patterns from Laser-Induced Azido Photochemistry of SpinLabeled Photoaffinity ATP Analogs in Matrix-Assisted Saser Desorption/Ionization Mass Spectrometry. J. Am. Soc. Mass Spectrom. 1999, 10, 1337-1340. 